\title{
DISCURSO DE MULHERES NA EXPERIÊNCIA DO PARTO CESÁREO E NORMAL
}

\section{WOMEN'S DISCOURSE ON EXPERIENCE CESAREAN AND VAGINAL LABOR}

\author{
Antonio Rodrigues Ferreira Junior ${ }^{1}$, Francisca Alanny Arújo Rocha ${ }^{2}$, Jozianne Magna \\ Carneiro $^{2}$, Neires Alves Freitas ${ }^{3}$ \\ Universidade Estadual do Ceará ${ }^{1}$; Instituto Superior de Teologia Aplicada ${ }^{2}$; Universidade Estadual do Rio de Janeiro ${ }^{3}$
}

\begin{abstract}
This study analyzed the experience of women who have been through vaginal and caesarean deliveries. This is a descriptive, qualitative exploratory study, held in a small municipality of the state of Ceará, Brazil, in 2015, with nine women who experienced both types of delivery (vaginal and cesarean) and were selected through snowball sampling technique. The generated dialog in each individual interview was analyzed with the Discourse of the Collective Subject technique. It was identified that pain is an important factor for comparison between experiences with both types of labor, vaginal delivery presents to establish better memories for the women. It has to be suggested that normal delivery needs to be encouraged by health care professionals, highlighting the risks of cesarean delivery and the higher chances of complications in this procedure.
\end{abstract}

Key words: Comprehensive Health Care; Women; Obstetric delivery; Cesarean Section; Natural Childbirth.

\section{Resumo}

O presente estudo analisou a experiência de mulheres que protagonizaram partos normal $e$ cesáreo. Trata-se de uma pesquisa qualitativa de natureza exploratório-descritiva, realizada em município de pequeno porte do estado do Ceará, Brasil, no ano de 2015, com nove mulheres que vivenciaram partos por ambas as vias (vaginal $e$ cesárea) e foram selecionadas através da técnica de bola de neve. Os discursos gerados nas entrevistas individuais foram analisados com a técnica do Discurso do Sujeito Coletivo. Foi identificado que a dor é um fator importante para a diferenciação entre as experiências com os dois tipos de parto, bem como o parto normal apresenta-se como o que propicia melhores lembranças para as mulheres. Pode-se inferir que o parto normal precisa ser incentivado pelos profissionais de saúde, destacando os riscos da cesárea e as maiores chances de complicações neste procedimento.

Palavras chave: Assistência Integral à Saúde; Mulheres; Parto Obstétrico; Cesárea; Parto normal. 
Introdução

O parto é um dos momentos mais importantes na vida de uma mulher, uma vez que concretiza sua espera por tornar-se mãe ${ }^{1}$. 0 processo gravídico-puerperal não é apenas um acontecimento biológico, pois envolve fatores culturais, econômicos e emocionais, marcando a vida da mulher e de seus familiares ${ }^{2}$.

A institucionalização hospitalar do parto fez com que este processo íntimo perdesse sua naturalidade, passando a acontecer em meio a desconhecidos, em um local com normas e regras ${ }^{1}$. Nesta perspectiva, a Organização Mundial de Saúde (OMS) recomenda que a interferência do profissional de saúde durante o parto aconteça apenas quando indispensável, enfatizando que o propósito da atenção ao parto é garantir a segurança materna e neonatal mantendo saudáveis a mulher e o recémnascido, com o mínimo possível de intervenções médicas ${ }^{3}$.

O Ministério da Saúde (MS) afirma que o parto normal é mais seguro comparado ao cirúrgico, pois apresenta menos riscos de infecções, hemorragias, prematuridade e complicações gerais, além de favorecer a produção do leite materno através da liberação de hormônios como a prolactina e a ocitocina que são fabricados durante o trabalho de parto ${ }^{4}$.

No Brasil, o modelo de assistência ao parto tem se mostrado inadequado, pois ultrapassa a taxa de cesarianas sugerida pela normatização da OMS, que é de $15 \%$. Denota não se relacionar aos reais riscos obstétricos e sim, a fatores sociais, culturais e econômicos que influenciam na escolha do tipo de parto ${ }^{5}$.

Outro fator que eleva o índice de cesarianas no país é a ineficiência da assistência direcionada ao parto normal, que não atende as recomendações das evidências científicas. Isso causa experiências desagradáveis e traumáticas às mulheres, por impedi-las de protagonizar o momento de parir, tornando-as dependentes, frágeis e desrespeitando o ritmo natural do seu corpo, o que degrada o modelo de parto humanizado, propiciador de situações com intervenção profissional mínima ${ }^{6}$.

Os movimentos pela humanização ao parto iniciaram permeados por questionamentos sobre a qualidade da assistência durante este processo. Deste modo, surgiram novas propostas para o cuidado ao parto e nascimento, estabelecendo algumas recomendações, desfazendo-se de rotinas obstétricas dispensáveis, valorizando a mulher como protagonista, assistindo-a com um olhar integral. No Brasil, esse processo teve potência ampliada com a criação do Programa de Humanização no Pré-Natal e Nascimento (PHPN), pelo Ministério da Saúde ${ }^{7}$.

Salienta-se que a gravidez e o parto são acontecimentos únicos carregados de fortes sentimentos, por isso, todos os profissionais devem proporcionar um ambiente seguro e acolhedor aos envolvidos. A mulher deve receber cuidados individualizados e flexíveis de acordo com suas demandas, pois é necessário que se sinta segura e protegida por todos aqueles que a cercam. Do pré-natal ao parto, a presença do companheiro ou outro membro da família deve ser encorajada ${ }^{6}$.

Neste âmbito, em 2011, o Governo Federal lançou a Rede Cegonha (RC), uma estratégia para garantir saúde e qualidade de vida à mulher durante a gestação, parto e puerpério, além do desenvolvimento da criança até os dois anos de vida. A estratégia objetiva reduzir a mortalidade materna e infantil e garantir os direitos sexuais e reprodutivos de mulheres, homens, jovens e adolescentes. A proposta qualifica os serviços ofertados pelo Sistema Único de Saúde (SUS) no planejamento familiar, na confirmação da gravidez, no pré-natal, no parto e no puerpério ${ }^{5}$.

A discussão sobre a melhor forma de parir é comum nos serviços de saúde, causando necessidade da construção de argumentos que otimizem a tomada de decisão por parte dos profissionais e das mulheres envolvidas. Estudar as vivências que permeiam o parto é essencial para a otimização das práticas profissionais voltadas à humanização deste momento.

O objetivo deste estudo foi analisar a experiência de mulheres que protagonizaram partos normal e cesáreo. Esta pesquisa destacase por discutir as diferenças e similaridades adjacentes a estas vias de parto, por meio da perspectiva de quem o vivencia, o que possibilita melhor entendimento sobre este processo.

\section{Método}

Estudo exploratório-descritivo, de abordagem qualitativa ${ }^{8}$, realizado em município de pequeno porte, na região Norte do Estado do Ceará.

A escolha do município ocorreu pelo elevado índice de cesáreas no ano de 2014, com 154 (41,5\%) partos por esta via, dentre os 372 realizados; uma taxa bastante acima do percentual de $15 \%$ preconizado pela OMS, 
conforme dados revelados pelo Departamento de Informática do SUS ${ }^{9}$.

Participaram do estudo nove mulheres que atenderam aos seguintes critérios de inclusão: residentes no município; alfabetizadas; idade igual ou superior a 18 anos e que tenham vivenciado ambos os tipos de parto (normal e cesárea), não identificando aborto ou parto prematuro como parto normal.

A coleta de informações ocorreu por meio de entrevistas individuais que visam estimular a narrativa principal do entrevistado, sendo utilizadas prioritariamente em métodos qualitativos $^{10}$. Realizadas nos meses de outubro e novembro de 2015, foram gravadas e aconteceram na residência das participantes, com horário e data acordados previamente.

A amostragem ocorreu por meio da técnica de bola de neve, que consta da indicação das possíveis participantes por cada entrevistada. A primeira indica a próxima e assim sucessivamente até o alcance do ponto de saturação, que consiste na repetição de respostas já encontradas nas entrevistas anteriores ou a ausência de informações relevantes para a pesquisa ${ }^{11}$.

Obedecendo aos critérios de inclusão do estudo, a primeira participante entrevistada foi indicada pela enfermeira da equipe de Estratégia de Saúde da Família do setor Sede III, por ser esta a unidade de maior abrangência territorial no município, sendo realizada uma entrevista narrativa, com uma questão gerativa: "Conte um pouco de sua experiência com o parto cesáreo e vaginal. A melhor maneira de você fazer isso seria começar pelo início de cada gestação que já teve. Você pode levar o tempo que for preciso, pois todos os detalhes serão importantes para nossa pesquisa".

Adotou-se para análise o Discurso do Sujeito Coletivo (DSC) ${ }^{12}$, que se orienta pelas Expressões Chave (EC), Ideias Centrais (IC) e por fim, pela constituição do discursos do sujeito coletivo. Estes se apresentam como principais operadores metodológicos do DSC. As EC são trechos literais dos depoimentos, que sinalizam os principais conteúdos das respostas; as IC são fórmulas sintéticas, que nomeiam os sentidos de cada depoimento e de cada categoria de depoimento, e o DSC, os signos compostos pelas categorias e pelo seu conteúdo, ou seja, as EC que apresentam IC semelhantes agrupadas numa categoria.

Os dados foram organizados através da transcrição dos discursos gravados nas entrevistas, adotando a metodologia do DSC ${ }^{13}$. Após a organização dos dados e reflexão acerca do DSC foram definidos os seguintes temas: Experiência e satisfação com o parto normal; Experiência e satisfação com o parto cesárea; $A$ dor relacionada ao tipo de parto; A assistência pré-natal influencia a opção pela via de parto; $A$ opção pelo parto cesáreo justificada pela realização da laqueadura tubária. Estes foram organizados em quadros para melhor compreensão do leitor.

Com o intuito de garantir o anonimato e sigilo da identidade das mulheres, a identificação aconteceu com código alfanumérico, de forma a substituir o nome destas pela letra $\mathrm{P}$, em alusão ao nome participante, seguido de número arábico em ordem crescente (P1, P2, P3...).

$\mathrm{O}$ estudo respeitou as diretrizes e normas éticas previstas na Resolução 466/12 do Conselho Nacional de Saúde sobre pesquisas que envolvem seres humanos ${ }^{14}$, sendo aprovado pelo Comitê de Ética em Pesquisa da Universidade Estadual Vale do Acaraú, sob no. CAAE: 46507315.4.0000.5053.

\section{Resultados}

\section{Experiência e satisfação com o parto normal}

Nesta categoria a IC (Experiência e satisfação com o parto normal) reúne sentidos dos discursos das mulheres sobre a vivência do parto normal, gerada através das EC do Quadro 1.

Quadro 1 - Expressões Chave geradas a partir das experiências de mulheres com o parto normal.

\begin{tabular}{|l|l|}
\hline Participantes & \multicolumn{1}{|c|}{ Expressões Chave } \\
\hline P1 & "O parto normal é o melhor parto que tem." \\
\hline P2 & "Eu gostei do parto normal." \\
\hline P5 & $\begin{array}{c}\text { "Sobre o parto normal é muito bom para a mulher ter, porque não fica depois sentindo dor. O } \\
\text { normal você tem o filho, volta para casa e está boa." }\end{array}$ \\
\hline P8 & "Não tenho nada ruim pra falar do parto normal, ao contrário da cesárea." \\
\hline P9 & "No parto normal, depois a gente pode andar, pode pegar a criança, pode amamentar." \\
\hline
\end{tabular}

Fonte: primária. 
A identificação de componentes que contribuem para a satisfação das mulheres e os fatores que influenciam a escolha pelo tipo de parto é necessária para uma adequação da assistência prestada nos serviços de saúde, especialmente, quando se pretende estimular a opção pelo parto normal, que representa a minoração dos riscos relacionados à gestante e feto ${ }^{6}$.

Desta forma, os resultados aqui apresentados buscam revelar a experiência com o parto normal desvelando a satisfação ou não das mulheres que o experienciaram. Segue o DSC 1:

"Sobre o parto normal é muito bom para a mulher ter, porque não fica depois sentindo dor, o normal você tem o filho, volta para casa tá boa, depois a gente pode andar, pode pegar a criança, pode amamentar, não tenho nada ruim pra falar do parto normal, ao contrário da cesárea. Se você tem a possibilidade de ter um filho normal, jamais tenha um filho por cesárea, eu gostei do parto normal, é o melhor parto que tem".

Por meio do discurso, percebe-se satisfação com a experiência do parto normal nas mulheres que o vivenciaram. $\mathrm{Na}$ análise evidencia-se a rápida recuperação materna no puerpério e o sentimento de bem-estar, pela ausência de dor e condição fisiológica para o cuidado com o filho e o próprio corpo. Ademais, há a recomendação e aconselhamento deste parto para as outras mulheres que possuem a opção de escolha.

Dentre as vantagens do parto normal destacam-se ainda o menor tempo de internação hospitalar e a possibilidade de cuidado direto das mães com seu bebê no ambiente familiar próximo as pessoas que amam. Isso permite maior sensação de segurança, considerando este momento de grande relevância para o vínculo mãe e filho.

\section{Experiência e satisfação com o parto cesárea}

No que diz respeito à experiência com o parto cesáreo, a compilação de fragmentos dos discursos revela fatores negativos e positivos, sendo este último sobreposto, o que denota uma experiência negativa, na sua totalidade (Quadro 2). Segue o DSC 2:

“O parto cesariano, você não sente dor nenhuma, mas o pós é que é o pior. Achei ruim o resguardo, em cima de uma cama, não se mexe pra nada, a recuperação é mais dolorosa. Não gostei não, parto cesárea é ruim demais. Mas achei ponto positivo porque eu não sentia cólica, a gente fica assim super mais limpa, não vem aquela menstruação muito muito forte como a de parto normal. Mas quase morro, não é nada bom não, parto cesárea só quando tem realmente indicação."

Ao analisar o DSC observa-se a insatisfação das mulheres com o parto cesáreo, influenciada especialmente pelo pós-operatório. Os relatos evidenciam impossibilidade de movimentação, desconforto e recuperação lenta e dolorosa. Mesmo com algumas vantagens como "sentir-se mais limpa" e não sentir as dores no processo, o método não agrada as mulheres, que enfatizam a escolha por outra via de parto como prioritária.

Quadro 2 - Expressões Chave que geraram o DSC 2, embasado na Ideia Central das experiência de mulheres com a cesárea.

\begin{tabular}{|l|l|}
\hline Participantes & \multicolumn{1}{|c|}{ Expressões Chave } \\
\hline P1 & $\begin{array}{l}\text { "Mas não é muito bom o parto cesariano, você não sente dor nenhuma, mas o pós é que é o } \\
\text { pior." }\end{array}$ \\
\hline P3 & $\begin{array}{l}\text { "Na cesariana, só achei ruim o resguardo, em cima de uma cama, não se mexe pra nada e tomei } \\
\text { agulhadas." }\end{array}$ \\
\hline P4 & $\begin{array}{l}\text { "Aí quando foi o dia marcado fui fazer. A recuperação eu achei bom e ruim, mas achei mais ponto } \\
\text { positivo porque eu não sentia cólica, a gente fica assim super mais limpa, não vem aquela } \\
\text { menstruação muito, muito forte como a de parto normal." }\end{array}$ \\
\hline P5 & "Não gostei não, parto cesárea é ruim demais. Pra mim foi muito ruim, não sei para os outros." \\
\hline P6 & "A cesariana foi bem. A recuperação é mais dolorosa, mas não achei tão ruim." \\
\hline P7 & "Mas quase morro, não é nada bom não a cesariana." \\
\hline P8 & $\begin{array}{l}\text { "Recomendo quem pode parir normal, parir normal, que parto cesárea só quando tem realmente } \\
\text { indicação." }\end{array}$ \\
\hline
\end{tabular}

Fonte: primária. 


\section{A dor relacionada ao tipo de parto}

Na realização de um comparativo sobre as citadas vias de parto, observou-se que as próprias participantes o fazem de maneira explícita em suas falas, discorrendo sobre ambos em relação à recuperação. Informam que no parto normal é rápida e indolor e na cesariana torna-se dolorosa e tardia. Outro aspecto evidenciado é a mobilidade prejudicada após a cesariana, pois afirmam que influencia em aspectos importantes como segurar o bebê, amamentar e realizar suas necessidades básicas (Quadro 3). Além destes fatores, enfatizam comparações sobre a dor, como se identifica no discurso a seguir.

Quadro 3 - Expressões Chave geradas nos discursos das mulheres acerca da Ideia Central da dor relacionada ao tipo de parto.

\begin{tabular}{|l|l|}
\hline Participantes & \multicolumn{1}{|c|}{ Expressões Chave } \\
\hline P1 & $\begin{array}{l}\text { "É uma dor passageira, só são as contrações mesmo que atrapalham, mas é uma dor que dá pra } \\
\text { suportar." }\end{array}$ \\
\hline P2 & $\begin{array}{l}\text { "Com pouco tempo lá eu tive ele normal. Gostei, pois as dores eram passageiras, contrações, } \\
\text { rapidinho passou." }\end{array}$ \\
\hline P3 & $\begin{array}{l}\text { "O que eu senti foi tão diferente que eu nem sei dizer, fiquei admirada. Eu não senti nada, levei } \\
\text { ponto, eles cortaram lá pra me ajudar, mas nem isso eu senti não sei se era a animação e a } \\
\text { adrenalina que eu não senti nada." }\end{array}$ \\
\hline P3 & $\begin{array}{l}\text { "Todo dia eu sentia dor. Eu sentia muita dor de cabeça no meu resguardo e as dores só } \\
\text { passavam com injeção na veia." }\end{array}$ \\
\hline P5 & $\begin{array}{l}\text { "Sofri que só. Comecei a sentir uma hora da manhã vim ter a menina uma hora da tarde." } \\
\text { "Agora já a cesariana você não sente dor na hora, mas depois é bem pior, as dores, o }\end{array}$ \\
\hline P5 & $\begin{array}{l}\text { "Senti dor até o último dia do meu resguardo, a minha cirurgia ficou inflamada. Todo dia eu } \\
\text { sentia dor." }\end{array}$ \\
\hline P9 & \\
\hline
\end{tabular}

Fonte: primária.

Nas reflexões sobre a dor relacionada ao tipo de parto, as participantes argumentam que no parto normal, é intensa, porém suportável e passageira. Ao contrário da cesariana, que não ocorre durante o procedimento, porém no pósparto está presente.

"Sofri que só. Comecei a sentir uma hora da manhã vim ter a menina uma hora da tarde, as dores eram passageiras, contrações, é uma dor que dá pra suportar, levei ponto, eles cortaram lá pra me ajudar. Quando nasceu foi só alegria, não sei se era a animação e a adrenalina que eu não senti mais nada. Agora já a cesariana você não sente dor na hora, mas depois é bem pior, as dores o incômodo, senti dor até o último dia do meu resguardo, a minha cirurgia ficou inflamada. Todo dia eu sentia dor. Eu sentia muita dor de cabeça no meu resguardo e as dores só passavam com injeção na veia".

\section{A assistência pré-natal influencia a opção pela via de parto}

Um aspecto importante identificado nesta pesquisa foi que mesmo as mulheres relatando satisfação com o parto normal, em uma oportunidade posterior algumas optariam pela cesariana, influenciadas por outros fatores apresentados nesta categoria (Quadro 4).

As informações recebidas pelas mulheres durante a assistência ao trabalho de parto e parto apresentaram uma clara associação com a satisfação com o evento, com exceção da comunicação relativa à medicação recebida. As demais, tais como: evolução do trabalho de parto, bem-estar do feto e exames realizados, foram associados a contentamento com o processo de cuidado.

"Eu tinha muito medo, não tinha experiência, era bem novinha. Mas aí eu fiz meu pré-natal direitinho e foi muito bom, acompanhado por quatro médicos e aí eu não tive uma pressão de fazer nem cesariana e muito menos o parto normal. Fiz algumas ultrassons, ele no oitavo mês estava sentado eu não tinha nem condições de ter normal, eu tive infecção urinária e anemia muito alta, como eu tinha vergonha do enfermeiro, por ele ser homem eu não contava tudo que sentia. Aí fiz meu pré-natal todo mês, aí o médico marcou o dia da minha cesárea". 
Percebe-se neste discurso a relação entre a assistência pré-natal e a escolha da via de parto, pois as entrevistadas expressam em seus relatos a importância de ser acompanhada, orientada e assistida por profissionais que realmente informem sobre o assunto, evidenciando riscos e vantagens de cada método e respeitando as peculiaridades da gestante e suas necessidades.

Quadro 4 - Expressões Chave geradas nos discursos com a Ideia Central acerca da assistência pré-natal e as influências sobre a opção pela via de parto.

\begin{tabular}{|l|l|}
\hline Participantes & \multicolumn{1}{|c|}{ Expressões Chave } \\
\hline P1 & $\begin{array}{l}\text { "Foi um pré-natal muito bom, acompanhado por quatro médicos e aí eu não tive uma } \\
\text { pressão de fazer nem cesariana e muito menos o parto normal, ele foi espontâneo } \\
\text { mesmo." }\end{array}$ \\
\hline P3 "O meu pré-natal não foi muito bom, fiz algumas ultrassons, ele no oitavo mês estava \\
$\begin{array}{l}\text { sentado eu não tinha nem condições de ter normal. Eu tive infecção urinária e anemia } \\
\text { muito alta, como eu tinha vergonha do enfermeiro, por ele ser homem eu não contava } \\
\text { tudo que sentia." }\end{array}$ \\
\hline P4 & $\begin{array}{l}\text { "Eu tinha muito medo, não tinha experiência, era bem novinha. "Mas aí eu fiz meu pré- } \\
\text { natal direitinho e foi muito bom." }\end{array}$ \\
\hline P5 & $\begin{array}{l}\text { "Aí fiz meu pré-natal todo em Fortaleza, todo mês ia aí o médico marcou o dia da minha } \\
\text { cesárea." }\end{array}$ \\
\hline
\end{tabular}

Fonte: primária.

\section{A opção pelo parto cesáreo justificada pela realização da laqueadura tubária.}

Observa-se que o desejo de realizar a contracepção definitiva faz com que as mulheres optem pelo parto cesáreo, no intuito de "não sofrer duas vezes" e "aproveitar a cirurgia para a retirada da criança". Isso contribui para que o nascimento aconteça de forma medicalizada e esteja suscetível aos riscos de um procedimento cirúrgico (Quadro 5).

“Já na segunda gravidez eu optei pra ser cesariana, o meu menino tava com cinco meses eu descobri que eu já estava grávida de novo aí eu mesmo fui atrás pra conseguir a ligação e eles não queriam porque diziam que eu era nova e poderia ter mais filho, aí eu expliquei a situação até que eu consegui. Fiz o pré-natal como eu já ia fazer a ligação foi cesárea."

Observa-se neste discurso que as mulheres mesmo satisfeitas com uma experiência anterior de parto normal, diante da opção de escolha do tipo de parto optaram por cesariana para a realização de laqueadura tubária, pela vontade ou necessidade de um método contraceptivo definitivo.

Quadro 5 - Expressões Chaves geradas nos discursos das mulheres sobre a Ideia Central da opção pelo parto cesáreo justificada pela realização da laqueadura tubária.

\begin{tabular}{|l|l|}
\hline Participantes & \multicolumn{1}{|c|}{ Expressões Chave } \\
\hline P1 & $\begin{array}{l}\text { "Já na segunda gravidez eu optei pra ser cesariana, porque eu queria que fosse feito a } \\
\text { laqueadura." }\end{array}$ \\
\hline P4 & $\begin{array}{l}\text { "A mãe me aconselhou a fazer cesárea e a ligação, aí eu mesmo fui atrás com ela pra conseguir } \\
\text { e eles não queriam porque diziam que eu era nova e poderia ter mais filho, aí eu expliquei a } \\
\text { situação até que eu consegui." }\end{array}$ \\
\hline P5 & "Fiz o pré-natal e como eu já ia fazer a ligação, foi cesárea." \\
\hline P9 & $\begin{array}{l}\text { "E aí a cesariana eu tive da minha terceira gravidez que foi uma menina, o meu menino tava } \\
\text { com cinco meses eu descobri que eu já estava grávida de novo, aí eu fui resolvi fazer } \\
\text { laqueadura." }\end{array}$ \\
\hline
\end{tabular}

Fonte: primária.

\section{Discussão}

Imediatamente após o parto normal, fluem sentimentos de alívio, contentamento e felicidade, especialmente pela superação da dor e do medo e, por ter o filho em seus braços. Durante este período a mulher vivencia uma mudança de caráter físico e emocional, que pode ser compreendido pelas fácies de alívio com a redução das dores após a saída do concepto ${ }^{15}$.

O momento em que a parturiente contempla a face de seu filho é importante, pois ela o reconhece como parte sua. O bebê passa a concentrar a atenção materna devido à expectativa, dificuldade e alegria que permearam a sua chegada. 
A dor conserva-se como o item mais relembrado na parturição, porém quando relacionada à via de parto, as mulheres apontam a dor do parto normal como presente em todo o momento, contudo tolerável, permitindo o retorno às suas rotinas precocemente. Por outro lado, no parto cesáreo, a dor ausenta-se inicialmente, mas aparece em decorrência do procedimento de maneira persistente e incapacitante ${ }^{16-17}$.

A dor para essas mulheres foi o item mais recordado, apesar de algumas experiências terem ocorrido há alguns anos. Muitas mulheres fazem referência à dor como algo que ficou registrado de forma marcante na memória e que pode ser relembrada com clareza ${ }^{18}$. Assim, de um modo ou de outro, o parto continua relacionado à dor, sendo essa referida como manifestação e influência negativa durante este processo. Isso contribui com a ampliação do número de cesáreas $^{19}$.

Além do aumento da morbimortalidade materna e neonatal, as cesáreas originam outros problemas como a infecção puerperal e a prematuridade. Também se associam com um retardo na recuperação puerperal, maior tempo de internação e assistência por profissionais de saúde, maior uso de medicamentos, início tardio da amamentação e, por fim, elevação de gastos para o sistema de saúde ${ }^{20}$.

Neste contexto, a maioria das mulheres se revela insatisfeita com a cesárea, pois 0 momento acaba por se tornar patológico e se distancia do seu verdadeiro significado. Quanto mais completa ou suficiente à informação percebida pela mulher, maior a satisfação relatada com a assistência ao parto ${ }^{21}$. Percebeuse ainda que embora a escolha do tipo de parto pela mulher ainda não ocorra em todo o Brasil, o Ministério da Saúde tem recomendado este processo.

Quanto às causas do alto índice de cesáreas, pode-se citar o pouco tempo destinado pelo médico obstetra para assistir o trabalho de parto, em consequência de atividades concomitantes que exerce na prática médica. Ademais o despreparo do médico, formado para intervir, a falta de conhecimento da mulher sobre o parto vaginal, a desinformação sobre a indicação da cesárea anterior, e a carência de enfermeiras obstétricas para assistir o parto, a realização da laqueadura tubária durante a cesariana, entre outras, influenciam a opção por esta via de parto $^{22}$.

Destaca-se que a cesárea torna a mulher dependente e passível de complicações nos momentos de parto e pós-parto, com maior risco de morbidade. Nesta conjuntura, deve ser realizada apenas quando houver indicações reais de sua necessidade, após análise acurada dos processos fisiopatológicos que permeiam a situação.

\section{Conclusão}

As informações obtidas nos Discursos do Sujeito Coletivo demonstraram que a experiência nos dois tipos de parto confirma a satisfação e preferência pelo parto normal, embora os índices de cesariana estejam elevados.

Percebe-se que, como preconizado pelo Ministério da Saúde, o melhor tipo é o parto normal, por ser considerado mais saudável para mãe e bebê. Também por apresentar menores chances de complicações, sendo importante ressaltar que este evento natural é fisiológico e que a mulher não deve ser fragilizada e retirada do papel de protagonista neste processo.

Os resultados evidenciaram que as mulheres expressam em sua maioria, a satisfação e a preferência pelo parto normal e relatam insatisfação com os aspectos relacionados ao pós-operatório do parto cesáreo. Apresentam a dor como principal comparativo entre os dois tipos de parto, e explicam que a escolha do método de parir está relacionada a aspectos como esterilização cirúrgica e ao aconselhamento pré-natal.

Neste âmbito, o parto normal precisa ser incentivado pelos profissionais de saúde, informando as gestantes durante o acompanhamento pré-natal e o trabalho de parto, destacando os reais riscos da cesárea e as maiores chances de complicações deste procedimento, que deverá ser realizado apena quando houver indicação.

As limitações do estudo se apresentam por denotar uma realidade específica e pela desinformação encontrada em algumas mulheres acerca dos benefícios dos tipos de parto, no entanto, apresenta um cenário que permite reflexão acerca dos desafios profissionais na área da saúde, para o desenvolvimento de práticas pautadas por evidências científicas no parto e nascimento.

\section{Referências}

1. Chaves RL. O nascimento como experiência radical de mudança. Cad. Saúde Pública. 2014;30 sup:S14-S16. 
2. Cicuto AG, Belisário CRL, Tavares BB. Puerperal women's satisfaction with their delivery. Invest Educ Enferm. 2012; 30(2): 20814.

3. Dias MA, Domingues RM, Schilithz AO, Nakamura-Pereira M, Leal MC. Factors associated with cesarean delivery during labor in primiparous women assisted in the Brazilian Public Health System: data from a National Survey. Reprod Health. 2016; 13(Suppl 3):114.

4. Cavalcanti PCS, Gurgel Junior GD, Vaconcelos ALR, Guerrero AVP. Um modelo lógico da Rede Cegonha. Physis (Rio J.). 2013;23(4):1297-316.

5. Ministério da Saúde (BR). Rede cegonha: Gravidez, parto e nascimento com saúde, qualidade de vida e bem-estar. Brasília: Ministério da Saúde; 2013.

6. Ministério da Saúde (BR). Caderno HumanizaSUS: Humanização do parto e do nascimento. Brasília: Ministério da Saúde; 2014.

7. Scarton J, Prates LA, Barreto CN, Pompeu KC, Castiglioni CM, Ressel LB. O cuidado de enfermagem no trabalho de parto e parto: vivências de puérperas primíparas. Rev enferm UFPE on line., 2014;8(6):1820-3.

8. Minayo MCS. $O$ desafio do conhecimento: pesquisa qualitativa em saúde. São Paulo: Hucitec; 2010.

9. Departamento de Informática do SUS. [homepage na internet] [Acesso em 12 Jul 2016]. Disponível em:

http://datasus.saude.gov.br/sistemas-e-

aplicativos/eventos-v/sinasc-sistema-de-

informacoes-de-nascidos-vivos.

10. Flick U. Introdução à pesquisa qualitativa. Porto Alegre: Artmed; 2009.

11. Vinuto J. A amostragem em bola de neve na pesquisa qualitativa: um debate em aberto. Temáticas. 2014;22(44):203-20.

12. Lefevre F, Lefevre AMC. Depoimentos e discursos. Brasília: Liberlivro; 2005.

13. Lefevre $F$, Lefevre AMC. Discurso do sujeito coletivo: representações sociais e intervenções comunicativas. Texto \& Contexto Enferm. 2014;23(2):502-7.

14. Conselho Nacional de Saúde (BR). Resolução no. 466, de 12 de dezembro de 2012. Aprova as diretrizes e normas regulamentadoras de pesquisas envolvendo seres humanos. Diário Oficial da União. 13 dez 2012.

15. Boryri T, Noori NM, Teimouri A, Yaghobinia $F$. The perception of primiparous mothers of comfortable resources in labor pain (a qualitative study). Iran J Nurs Midwifery Res. 2016;21(3):239-46.
16. Velho MB, Santos EKA, Brüggemann OM, CamargoBV. Vivência do parto normal ou cesáreo: revisão integrativa sobre a percepção de mulheres. Texto \& Contexto Enferm. 2012;21(2): 458-66.

17. Orange FA, Passini-Jr R, Melo ASO, Katz L, Coutinho IC, Amorim MMR. Combined spinalepidural anesthesia and non-pharmacological methods of pain relief during normal childbirth and maternal satisfaction: a randomized clinical trial. Rev Assoc Med Bras. 2012;58(1):112-7.

18. Rei VAF, Ramírez XYA, Berlinck MT. As dores do parto. Reflexões psicopatológicas em torno da angústia e do narcisismo primitivo. Estilos clin. 2014; 19(1):67-77.

19. Silva SPC, Prates RCG, Campelo BQA. Parto normal ou cesareana? Fatores que influenciam na escolha da gestante. Rev. Enferm. UFSM. 2014;4(1):1-9.

20. Torres JA, Domingues RMSM, Sandall J, Hartz Z, Gama SGN, Theme Filha MM, et al. Cesariana e resultados neonatais em hospitais privados no Brasil: estudo comparativo de dois diferentes modelos de atenção perinatal. Cad. Saúde Pública. 2014;30 sup:S220-S231.

21. Almeida NAM, Medeiros M, Souza MR. Sentidos da dor do parto normal na perspectiva e vivência de um grupo de mulheres usuárias do Sistema Único de Saúde. Rev. Min. Enferm. 2012;16(2):241-50.

22. Gama SGN, Viellas EF, Schilithz AOC, Theme Filha MM, Carvalho ML, Gomes KRO, et al. Fatores associados à cesariana entre primíparas adolescentes no Brasil, 2011-2012. Cad. Saúde Pública. 2014;30 sup:S117-S127.

\section{Endereço para Correspondência}

Universidade Estadual do Ceará

e-mail: junioruruoca@hotmail.com

Recebido em 05/11/2016

Aprovado em 09/05/2017

Publicado em 30/06/2017 